\title{
Clinical and radiographic features of spondylitic hip disease
}

\author{
J. S. MARKS AND K. HARDINGE \\ From the Rheumatology Unit and the Centre for Hip Surgery, Wrightington Hospital, Wigan, Lancs
}

SUMMARY The clinical and radiographic features of hip disease in 76 patients with definite anky losing spondylitis have been studied. Symptomatic hip involvement occurred late in the course of the disease, with a mean delay after the onset of 12 years in males and 7 years in females. Patients withpo disease onset before the age of 20 developed hip symptoms at an earlier stage. Associated diseases included uveitis $(13 \%)$, colitis $(4 \%)$, and psoriasis (4\%). Bilateral concentric loss of hip joint space with a relatively undeformed femoral head was the commonest radiological change $(61 \%)$. Localisedf loss of joint space at the upper pole $(16 \%)$ was associated with femoral head destruction and a greater degree of osteophytosis, suggesting coincidental or secondary osteoarthrosis. Bony ankylosis of the hips $(10 \%)$ was present only in women, and the absence of osteophytes, cysts, and bone lesions of the iliac crests and ischial rami suggests that it is a distinct radiographic manifestation of female $e_{-\infty}^{\infty}$ ankylosing spondylitis.

Ankylosing spondylitis characteristically affects the sacroiliac joints and the spine, but peripheral joint involvement occurs in at least $50 \%$ of patients during the course of their disease (Polley and Slocumb, 1947; Wilkinson and Bywaters, 1958; Resnick, 1974). Involvement of the hip is particularly common (Forestier et al., 1956), with distinct radiographic appearances that may be used to distinguish spondylitic hip disease from that seen in rheumatoid arthritis or osteoarthrosis (Glick, 1966; Dwosh, et al., 1976). Hip disease in some patients may be more disabling than spinal rigidity and can be treated by total replacement arthroplasty (Welch and Charnley, 1970; Williams et al., 1977). The purpose of this study was to define the clinical and radiographic features of a group of patients with spondylitic hip disease admitted for total hip joint replacement.

\section{Patients and methods}

The medical records and pelvic radiographs of $\mathbf{7 6}$ patients with ankylosing spondylitis have been reviewed. The patients were consecutive admissions to Wrightington Hospital between January 1963 and December 1977 for total hip joint replacement. All the patients fulfilled the New York criteria for definite ankylosing spondylitis (Bennett and Wood, 1968).

Accepted for publication 31 July 1978

Correspondence to Dr J. S. Marks, Hope Hospital, Eccles Old Road, Salford M6 8HD.
Clinical details obtained from the medical records included age at onset of disease, site(s) of initiag symptoms, age at initial hip symptoms, associated diseases, previous medical and surgical treatment $\frac{\Phi}{\square}$ and details of hip surgery during admission.

Preoperative pelvic radiographs were graded bys the pattern of reduction of hip joint space, and 5 different patterns were recognised as shown (Figs. $1=$ 5). In 5 patients preoperative radiographs were no available, so that their hips could not be classified Protrusic acetabuli was recorded if the media margin of the acetabulum crossed the ilioischial line (tear drop line of Köhler). The presence of osteo phytes, subchondrial cysts, femoral head deformity, and bone lesions of the iliac crests, ischial rami, ando symphysis pubis were recorded.

\section{Results}

Seventy-six patients were included in the study $(550$ males and 21 females). The age and onset of spondy $-\omega$ litic symptoms was similar in both sexes, with a? mean age of 25 (range 9-56) in males and 22 (rangeo 16-51) in females. Table 1 shows the site of onsetw of symptoms and indicates that, although most. patients initially developed symptoms in the low back or buttocks and hips, in 8 men and 4 women hip involvement alone was the initial presenting? feature. The age of onset of hip symptoms was similaro in both sexes, with a mean age of 39 (range 9-72) in males and 35 (range 18-62) in females. Then 
interval between the onset of spondylitis and the development of hip symptoms was greater for men, with a mean interval of 12 years compared to 7 years for women, although in both groups the interval was

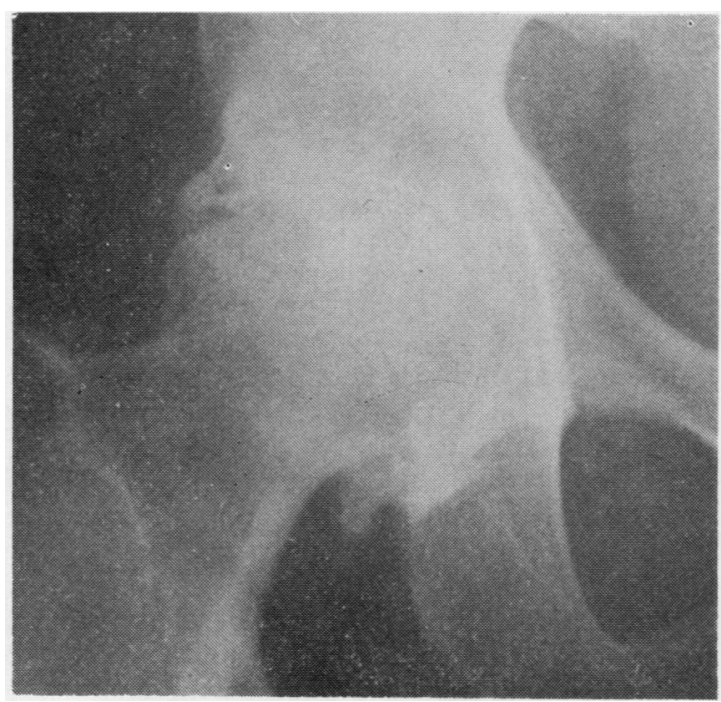

Fig. 1 Concentric: Concentric loss of joint space with moderate osteophytosis and undeformed femoral head

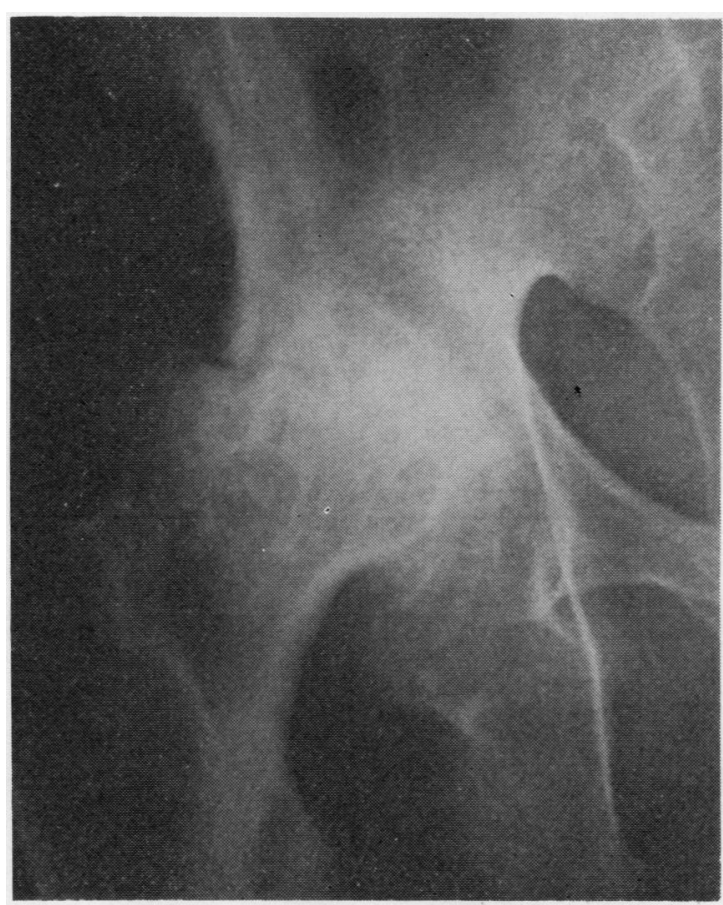

Fig. 2 Upper pole: Gross loss of head substance at upper pole and secondary subluxation shorter in those where initial spondylitic symptoms were present before the age of 20 (Table 2). Hip symptoms were bilateral from the onset in $40 \%$ of cases and were eventually bilateral in almost all.

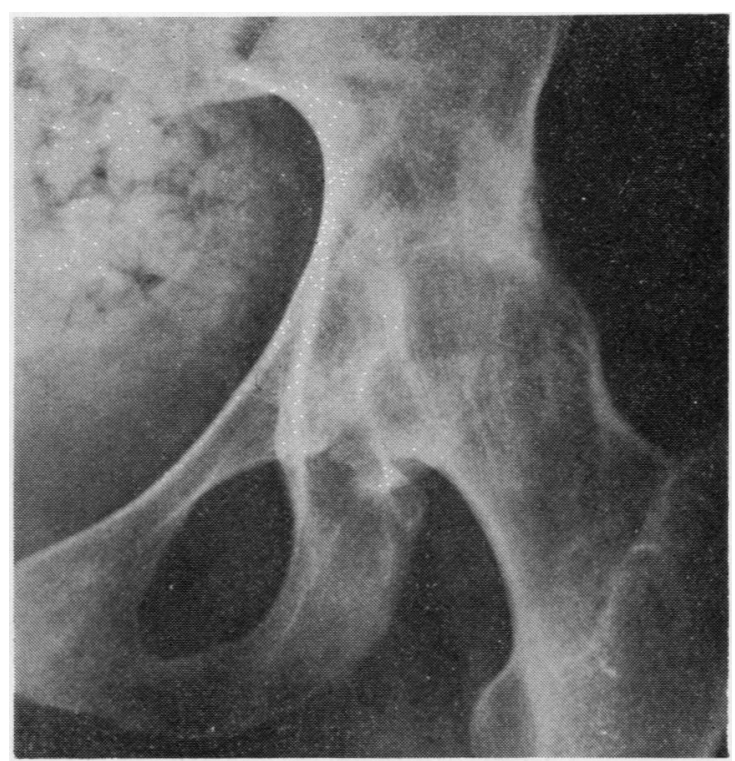

Fig. 3 Fused: Bony ankylosis of hip joint with minimal osteophytosis.

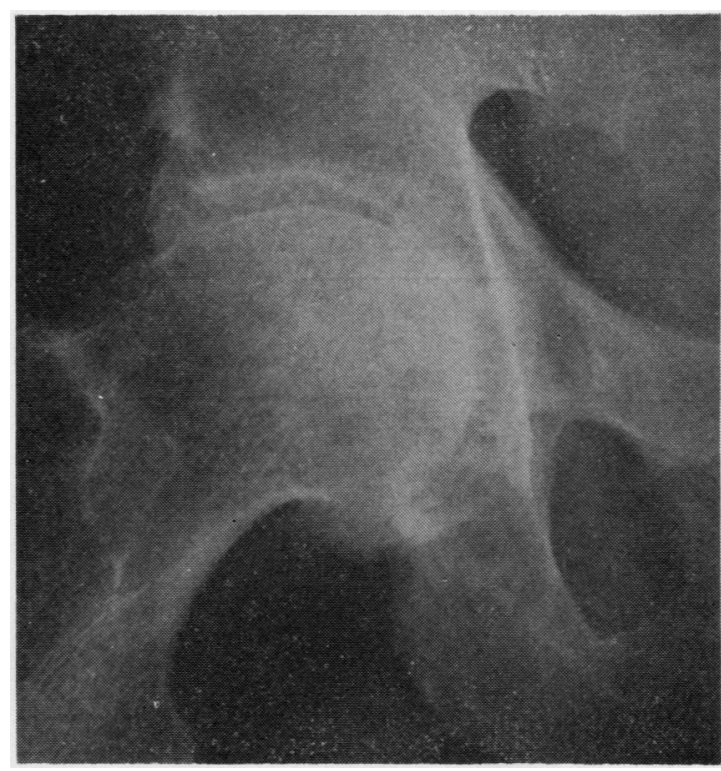

Fig. 4 Medial pole: Joint space is narrowed medially but preservation of joint space at upper pole. 
Analysis for associated diseases indicated a past history of uveitis in 10 patients $(13 \%, 9$ males, 1 female) colitis in $3(4 \%, 1$ male, 2 females $)$, and

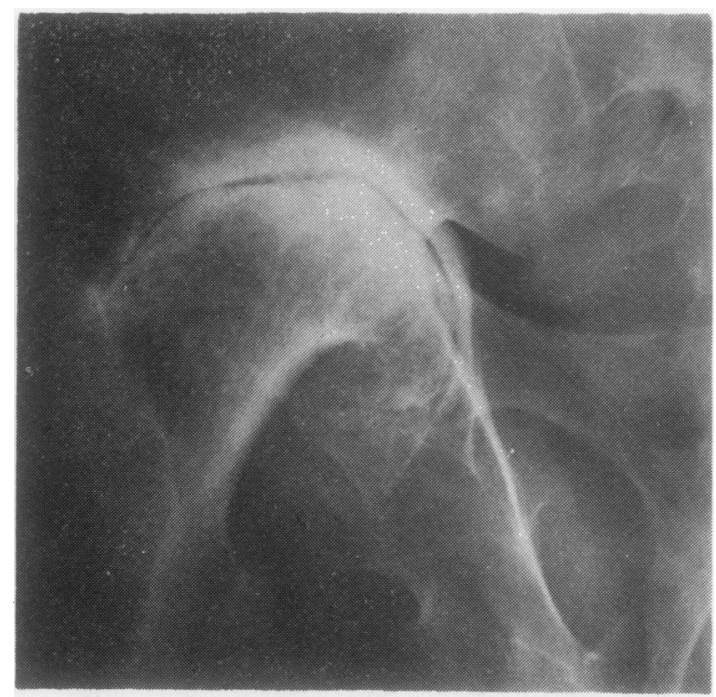

Fig. 5 Destructive: Generalised loss of head substance disproportionate to acetabular destruction. Sclerosis present, and joint space of sorts separating bones.

Table 1 Site of onset of symptoms

\begin{tabular}{lcc}
\hline & \multicolumn{2}{c}{ Number of cases } \\
\cline { 2 - 3 } & Male & Female \\
\hline Low backache & 12 & 3 \\
Buttocks and hips & 7 & 2 \\
Hips alone & 8 & 4 \\
Cervical spine & 0 & 1 \\
Knees & 5 & 0 \\
Shoulders & 0 & 1 \\
Feet & 1 & 0 \\
Polyarthritis & 3 & 0 \\
Unspecified & 21 & 10 \\
\hline
\end{tabular}

Table 2 Interval between onset of spondylitis and hip symptoms

\begin{tabular}{|c|c|c|c|c|c|c|c|}
\hline \multirow[t]{2}{*}{ Sex } & \multirow{2}{*}{$\begin{array}{l}\text { Age of onset } \\
\text { of spondy- } \\
\text { litis (years) }\end{array}$} & \multirow[t]{2}{*}{$\begin{array}{l}\text { Total no. } \\
\text { of patients }\end{array}$} & \multicolumn{5}{|c|}{$\begin{array}{l}\text { Delay before onset of hip } \\
\text { symptoms }(y r)\end{array}$} \\
\hline & & & 0 & $1-5$ & $6-10$ & $11-20$ & $>20$ \\
\hline Male & $\begin{array}{r}0-10 \\
11-20 \\
21-30 \\
31-40 \\
41-50 \\
51-60\end{array}$ & $\begin{array}{r}1 \\
14 \\
17 \\
7 \\
4 \\
1 \\
\text { No. with in }\end{array}$ & $\begin{array}{c}1 \\
6 \\
2 \\
1 \\
0 \\
1 \\
\text { nad }\end{array}$ & $\begin{array}{c}0 \\
0 \\
2 \\
0 \\
2 \\
0 \\
\text { quate }\end{array}$ & $\begin{array}{l}0 \\
2 \\
2 \\
1 \\
0 \\
0 \\
\text { letails }\end{array}$ & $\begin{array}{r}0 \\
4 \\
5 \\
3 \\
1 \\
0 \\
11\end{array}$ & $\begin{array}{l}0 \\
2 \\
6 \\
2 \\
1 \\
0\end{array}$ \\
\hline Female & $\begin{array}{r}0-10 \\
11-20 \\
21-30 \\
31-40\end{array}$ & $\begin{array}{c}0 \\
5 \\
8 \\
1 \\
\text { No. with in }\end{array}$ & $\begin{array}{c}0 \\
2 \\
3 \\
1 \\
\text { nad }\end{array}$ & $\begin{array}{c}0 \\
0 \\
1 \\
0 \\
\text { quate }\end{array}$ & $\begin{array}{l}0 \\
3 \\
1 \\
0 \\
\text { details }\end{array}$ & $\begin{array}{l}0 \\
0 \\
2 \\
0 \\
7\end{array}$ & $\begin{array}{l}\mathbf{0} \\
\mathbf{0} \\
1 \\
\mathbf{0}\end{array}$ \\
\hline
\end{tabular}

psoriasis in $3(4 \%, 2$ males, 1 female). Previous? medical treatment had included $x$-ray therap $\vec{F}$ ( 25 cases, 19 males, 6 females), steroids (17 cases 11 males, 6 females) immobilisation (10 cases, \& males, 2 females), and traction (11 cases, 7 males 4 females).

Hip surgery had previously been carried out in 10 patients and included osteotomy (1), excisior arthroplasties (3), cup arthroplasties (3), Fluor $\overrightarrow{0}$ arthroplasties (2), and an acrylic Judet arthroplasty (1). All patients were admitted for joint replacement and $48(63 \%)$ had bilateral replacements, includingu 5 cases that had previous hip surgery converted to low-friction arthroplasty. The mean age at the timeo of surgery was 44 (range 24-77) in males and 50 (range 31-67) in females, and the mean duration of hip symptoms prior to joint replacement was $\delta$ years in both sexes.

Table 3 shows the different patterns of loss of joint space noted in the hip radiographs. If 5 patient whose preoperative radiographs were not available and the 10 patients who had previous surgery are excluded, there are 61 pelvic radiographs available for analysis. Concentric loss of joint space withe minimal femoral head deformity was the commones: feature and was bilateral and symmetrical in $\mathbf{3 7}$ cases $(61 \%)$. When the patterns of radiographic changes were related to sex it was found that bilateral fusiorb of hips occurred only in females. Table 4 shows the relative frequency in the different radiologicas groups of osteophytosis, cyst formation, femora $\mathrm{B}$ head deformity, and lesions of the iliac crests? ischial rami, and symphysis pubis. In the concentriẹ. group osteophytes were common, particularly on the acetabular margins $(92 \%)$, but cystic lesions were less common and then usually femoral $(40 \%)$. The group of patients with localised loss of joint space at the upper pole showed femoral head destruction $(80 \%)$ and a greater tendency to osteophytosis and cystic lesions. Six patients with hip joint fusion

Table 3 Grading of hip radiographs

\begin{tabular}{|c|c|c|c|c|}
\hline Pattern of $x$-ray change & $\begin{array}{l}\text { Total no. } \\
\text { of cases } \\
(61)\end{array}$ & $\begin{array}{l}\text { Males } \\
\text { No. (44) }\end{array}$ & $\%$ & $\begin{array}{l}\text { Females } \\
\text { No. (I7) }\end{array}$ \\
\hline $\begin{array}{l}\text { Bilateral concentric } \\
15 \text { with bilateral protrusio } \\
17 \text { without protrusio } \\
5 \text { with unilateral protrusio }\end{array}$ & 37 & 29 & 66 & 8 \\
\hline Bilateral fused & 6 & $\mathbf{0}$ & $\mathbf{0}$ & 6 \\
\hline Bilateral upper pole & 5 & 4 & 9 & 1 \\
\hline $\begin{array}{l}\text { Mixed group } \\
7 \text { concentric upper pole } \\
1 \text { concentric fused } \\
1 \text { concentric destructive } \\
1 \text { concentric medial } \\
1 \text { bilateral destructive } \\
1 \text { upper pole fused }\end{array}$ & 13 & 11 & 25 & 2 \\
\hline
\end{tabular}


Table 4 Relation between pattern of loss of joint space and other radiographic features

\begin{tabular}{|c|c|c|c|c|c|c|c|c|c|c|}
\hline \multirow[t]{2}{*}{$\begin{array}{l}\text { Patterns of hip joint } \\
\text { space loss }\end{array}$} & \multirow[t]{2}{*}{$\begin{array}{l}\text { Total } \\
\text { no. }\end{array}$} & $\begin{array}{l}\text { Acetabular } \\
\text { osteophytes }\end{array}$ & $\begin{array}{l}\text { Femoral } \\
\text { osteophytes }\end{array}$ & $\begin{array}{l}\text { Acetabular } \\
\text { cysts }\end{array}$ & $\begin{array}{l}\text { Femoral } \\
\text { cysts }\end{array}$ & $\begin{array}{l}\text { Femoral head } \\
\text { deformity }\end{array}$ & $\begin{array}{l}\text { Iliac } \\
\text { crest }\end{array}$ & $\begin{array}{l}\text { Ischial } \\
\text { rami }\end{array}$ & $\begin{array}{l}\text { Symphysis } \\
\text { sclerosis }\end{array}$ & $\begin{array}{l}\text { Pubis } \\
\text { Fusion }\end{array}$ \\
\hline & & No. (\%) & No. (\%) & No. $(\%)$ & No. $(\%)$ & No. $(\%)$ & No. $(\%)$ & No. $(\%)$ & No. (\%) & No. $(\%)$ \\
\hline $\begin{array}{l}\text { Bilateral concentric } \\
\text { Bilateral upper pole } \\
\text { Bilateral fused hips }\end{array}$ & $\begin{array}{r}37 \\
5 \\
6\end{array}$ & $\begin{array}{c}34(92) \\
5(100) \\
0(0)\end{array}$ & $\begin{array}{l}28(76) \\
5(100) \\
0(0)\end{array}$ & $\begin{array}{l}6(16) \\
3(60) \\
0(0)\end{array}$ & $\begin{array}{l}15(40) \\
5(100) \\
0(0)\end{array}$ & $\begin{array}{l}3(8) \\
4(80) \\
0(0)\end{array}$ & $\begin{aligned} & 11(30) \\
& 3(60) \\
& 0(0)\end{aligned}$ & $\begin{array}{r}23(62) \\
3(60) \\
0(0)\end{array}$ & $\begin{array}{r}14(38) \\
3(60) \\
1(17)\end{array}$ & $\begin{array}{l}6(16) \\
1(20) \\
2(33)\end{array}$ \\
\hline
\end{tabular}

(bony ankylosis) had no evidence of osteophytosis or cystic changes. Bony changes in the iliac crests and ischial rami were common features present equally in the bilateral concentric and bilateral upper pole groups but were absent in the group with fused hips. Lesions of the symphysis pubis were noted in all groups, but there was a greater tendency to fusion in those patients with fused hips.

\section{Discussion}

The age and site of onset of symptoms were similar to those noted in other series. The mean interval between symptomatic hip involvement and disease onset was more than 10 years in men and 5 years in women, and only $38 \%$ of the whole group developed hip symptoms within 5 years. This late onset of symptomatic hip disease contrasts sharply with the early onset noted in other spondylitic series (Forestier et al., 1956; Wilkinson and Bywaters, 1958) and in particular with the $75 \%$ involvement within 5 years noted by Dwosh et al. (1977). There was, however, a tendency for patients whose spondylitis started at any earlier age to develop their hip symptoms sooner, and $45 \%$ of those with disease onset below 20 as opposed to $34 \%$ with onset above 20 developed hip symptoms within 5 years. The occurrence of hip symptoms as a late feature of spondylitis in this series may have been biased by selection of patients with advanced hip disease requiring surgery.

Uveitis was present in 10 patients $(13 \%)$. This is a lower incidence than the $20 \%$ noted in other series (Blumberg and Rogan, 1956) and may be explained by the retrospective nature of the present study. The frequency of colitis $(4 \%)$ and psoriasis $(4 \%)$ is comparable to that in other series (Fletcher and Rose, 1955; Meuwisson et al., 1978). Previous treatment with immobilisation $(13 \%)$ and traction $(14 \%)$ was noted particularly in patients with a long duration of symptoms before surgery.

The radiographic features of the abnormal hips in this study have been compared with those noted in two other studies of spondylitic hip disease (Table 5). The reduction of joint space was considered an essential criterion for the diagnosis of hip disease
Table 5 Comparison of hip radiographs with previous series

\begin{tabular}{llll}
\hline & This study & Glick (1966) & $\begin{array}{l}\text { Dwosh et al. } \\
(1976)\end{array}$ \\
\cline { 2 - 4 } & $\begin{array}{l}\text { 121 abnormal } \\
\text { hips }(\%)\end{array}$ & $\begin{array}{l}\text { I50 abnormal } \\
\text { hips (\%) }\end{array}$ & $\begin{array}{l}\text { 81 abnormal } \\
\text { hips }(\%)\end{array}$ \\
\hline Loss of joint space & 100 & 20 & 55 \\
Concentric loss & 70 & Not specified & 50 \\
$\begin{array}{l}\text { Superior (upper } \\
\text { pole) loss }\end{array}$ & 16 & Not specified & 6 \\
Protrusio acetabuli & 28 & 4 & 30 \\
Hip ankylosis & 10 & 12 & $2 \cdot 5$ \\
\hline
\end{tabular}

and may explain its greater frequency in this study, though this might have been expected because of the selection of cases with advanced disease requiring surgery.

A distinction between 2 types of hip involvement in ankylosing spondylitis was first suggested by Forestier et al. (1956). It has been confirmed that the commonest radiographic appearance is concentric loss of joint space, which is usually bilateral and symmetrical and is associated with a relatively undeformed femoral head. The smaller group of patients with upper pole loss of joint space and femoral head irregularity may represent patients who have coincidental osteoarthrosis or who have developed secondary osteoarthrosis as a consequence of earlier spondylitic hip disease.

Bony ankylosis has traditionally been regarded as the end result of spondylitis affecting the hip, and its low frequency in this study was a surprise in view of the end stage nature of the cases. Six patients, all women, had bilateral hip ankylosis (fusion) without femoral head deformity. Osteophytic and cystic changes were strikingly absent from this group, which appears to be a distinct radiographic entity not previously described as a feature of female spondylitis (Tyson et al. 1953; Hart and Robinson, 1959; Hill et al., 1976; Resnick et al., 1976). These 6 patients were indistinguishable from the other female patients in the series as regards the onset of spondylitis and hip symptoms, the involvement of other peripheral joints, and previous treatment. One of the 6 patients had necropsy evidence of ulcerative colitis, but there were no other associated diseases in the remaining 5 cases. 
Irregular periosteal new bone formation around the iliac crests and ischial rami was equally common in the groups with concentric and upper pole loss of joint space as was noted in the series of Dwosh et al. (1976), but this frequency was twice that reported in another large series in which pelvic radiographs were specifically examined for its presence (Wilkinson and Bywaters, 1958). This finding contrasts with the absence of 'periostitis' in the small group with fused hips and supports the view that this group is a distinct entity. Erosion and sclerosis of the symphysis pubis was another common finding in all groups, but bony ankylosis of the symphysis pubis was particularly common in the group with fused hips.

Hip disease is a common feature of ankylosing spondylitis and may occur at any time during its course. Treatment of spondylitic hip disease by low friction arthroplasty is now possible, and it is important to recognise that different radiographic patterns of hip involvement occur and could influence surgical results.

\section{References}

Bennett, P. H., and Wood, P. H. N. (1968). Population studies of the rheumatic diseases. Proceedings of the $3 \mathrm{rd}$ International Symposium, New York, 1966, p. 456. Excurpta Medica: Amsterdam.

Blumberg, B., and Rogan, C. (1956). The natural history of rheumatoid spondylitis. Medicine, 35, 1-31.

Dwosh, I. L., Resnick, D., and Becker, M. A. (1976). Hip involvement in ankylosing spondylitis. Arthritis and Rheumatism, 19, 683-692.

Fletcher, E., and Rose, F. C. (1955). Psoriasis spondylitica. Lancet, 1, 695-696.
Forestier, J., Jacqueline, F., and Rotes-Querol, J. (1956). Ankylosing Spondylitis. Translated by A. O. Desjardins. Charles C. Thomas: Springfield, Illinois.

Glick, E. N. (1966). A radiological comparison of the hip joint: In rheumatoid arthritis and ankylosing spondylitis. Proceedings of the Royal Society of Medicine, 59, 1229-O 1231.

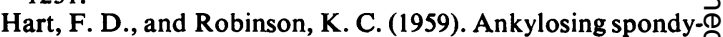
litis in women. Annals of the Rheumatic Diseases, 18, 15-

Hill, H. F. H., Hill, A. G. S., and Bodmer, J. G. (1976). Clinical diagnosis of ankylosing spondylitis in women andrelation to the presence of HLA-B27. Annals of the Rheumatic Diseases, 35, 267-270.

Meuwissen, S. G. M., Dekkar-Saeys, B. J., Agenant, D., ando Tytgat, G. N. J. (1978). Ankylosing spondylitis ando inflammatory bowel disease. Annals of the Rheumation Diseases, 37, 30-32.

Polley, H. F., and Slocumb, C. H. (1947). Rheumatoid spondylitis: a study of 1035 cases. Annals of Internak Medicine, 26, 240-249.

Resnick, D. (1974). Patterns of peripheral joint disease in ankylosing spondylitis. Radiology, 110, 523-532.

Resnick, D., Dwosh, I. L., Goergen, T. G., Shapiro, R. F., Utsinger, P. D., Weisner, K. B., and Bryan, B. L. (1976) Clinical and radiographic abnormalities in ankylosinge spondylitis: a comparison of men and women. Radiology, 119, 293-297.

Tyson, T. L., Thompson, W. A. L., and Ragan, C. (1953) Marie-Strümpell spondylitis in women. Annals of the Rheumatic Diseases, 12, 40-42.

Welch, R. B., and Charnley, J. (1970). Low friction arthroplasty of the hip in rheumatoid arthritis and ankylosing spondylitis. Clinical Orthopaedics and Related Research 72, 22-32.

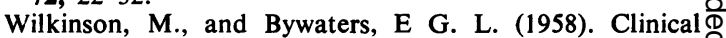
features and course of ankylosing spondylitis. Annals of the Rheumatic Diseases, 17, 209-228.

Williams, E., Taylor, A. R., Arden, G. P., and Edwards, D. HZ (1977). Arthroplasty of the hip in ankylosing spondylitis? Journal of Bone and Joint Surgery, 59B, 393-397. 